\title{
Liposome Vesicle
}

National Cancer Institute

\section{Source}

National Cancer Institute. Liposome Vesicle. NCI Thesaurus. Code C62384.

A microscopic vesicle consisting of one or more phospholipid layers surrounding an aqueous core. Liposomes can be utilized to facilitate the delivery of nanoparticles with attached therapeutic agents to biological targets such as specific cells or organs. 